\title{
O discurso pedagógico da ciência em operação na Rede Nacional de Educação e Ciência: Novos Talentos da Rede Pública (RNEC/NT)
}

\author{
The pedagogical discourse of science in operation \\ in the National Network of Education and Science: \\ New Talents of the Public System (RNEC/NT)
}

Lavínia Schwantes $^{1}$ • Paula Corrêa Henning ${ }^{1}$ • Paula Regina Costa Ribeiro ${ }^{1}$

\begin{abstract}
Resumo: Este artigo objetiva analisar como alguns grupos da Rede Nacional de Educação e Ciências: Novos Talentos da Rede Pública (RNEC/NT), da região sul do país, operam o que temos chamado discurso pedagógico da ciência em cursos para professores e estudantes da Educação Básica. Para tal, utilizamos descrições de cenas enunciativas de cursos desses grupos e os analisamos a partir da análise de discurso foucaultiana. Concluímos que existem três movimentos de pedagogização da ciência nos cursos analisados: na organização pedagógica geral do curso; no ensino, ou como denominamos na "pedagogização" do método científico; e na variação de metodologias para o ensino de ciências. É possível dizer que cursos como estes possibilitam ao professorado compreender a importância desses dois campos de saber para sua prática docente: o discurso pedagógico e o discurso científico.
\end{abstract}

Palavras- chave: Discurso científico. Discurso pedagógico. Curso de formação.

\begin{abstract}
This article aims to analyze how some groups of the Education and Science National Network/ New Talents of the Public System (RNEC/NT), from Southern Brazil, operate what we have called the pedagogical discourse of science in courses for teachers and students in Basic Education. To do this, we used descriptions of enunciative scenes courses taught to these groups and analyzed them using Foucault's discourse analysis. We concluded that there are three movements of science pedagogization in the analyzed courses: in the general pedagogical organization of the course; in teaching, or as we call "the pedagogization" of the scientific method; and in the variations of methods for teaching science. It is possible to mention that courses like these allow teachers to understand the importance of two fields in their teaching practice: the pedagogical discourse and the scientific discourse.
\end{abstract}

Keywords: Scientific discourse. Pedagogical discourse. Enhancement courses.

\footnotetext{
${ }^{1}$ Universidade Federal do Rio Grande (FURG), Rio Grande, RS, Brasil. E-mail: <laviniasch@gmail.com>.
} 


\section{Introdução}

$\mathrm{Na}$ vertente de estudos que temos trabalhado - pós-estruturalista com inspiração foucaultiana -, entendemos que os discursos são centrais na produção dos saberes, das subjetividades e da sociedade. Desta forma, atentamos, neste texto, para dois discursos que, dentre outros, balizam a sociedade moderna como a entendemos hoje: o discurso científico e o discurso pedagógico. A partir dos estudos arqueológicos de Foucault (2009a), entendemos que esses campos de saber possuem elementos e práticas discursivas que podem constituir-se em discursos específicos de cada campo, nomeados por sua forma e rigor, pelos objetos de que se ocupam, pelos tipos de enunciação que põem em jogo, assim como pelos conceitos e estratégias que utilizam.

Além disto, os discursos, ao serem produzidos dentro de um campo específico - como o pedagógico e/ou o científico - possuem determinadas regras de formação, de vigilância, de interdição, que são próprias do campo de saber a que pertencem. A produção dos discursos que circulam em nossa sociedade obedece a determinadas regras, ordenações, sanções, seleções para formalizar e orientar sua organização enquanto discurso específico (FOUCAULT, 2009a), orientação essa que é uma particularidade do projeto moderno.

Em relação ao discurso científico que compõe o campo de saber da ciência, salientamos que é considerado o regime de verdade de nossa época (FOUCAULT, 2009b). Como tal, este discurso produz grande parte das verdades do mundo, sendo legitimado por utilizar um método muito bem definido: o método científico. Tal método deriva-se de estudos, especialmente, de Bacon e Descartes. Sabemos, evidentemente, que há desdobramentos dessa concepção em outras e variadas formas de fazer ciência. No entanto, neste texto, pela análise do corpus discursivo desta investigação, tratamos especialmente do método científico a partir desses dois instauradores de discurso ${ }^{2}$. Esse método dá sustentação ao discurso científico, baseando-se nos pressupostos experimentais, no controle de variáveis, na produção de dados quantificáveis e na generalização dos mesmos. Devido ao efeito de certeza produzido por suas verdades, podemos entender que o discurso científico é uma das condições de possibilidade para a emergência da sociedade moderna, constituindo-se também como baliza que lhe dá sustentação, pois, com essas verdades, esse discurso coloca uma determinada ordem no mundo em que vivemos, tornando-o conhecido e previsível. Destacamos que essa ordenação do mundo, vislumbrada pela produção científica por meio de seu método, tem sido revista e problematizada por diferentes filósofos e historiadores da ciência contemporâneos, com os quais temos trabalhado em outros projetos e textos (HENNING, 2007, 2010; SCHWANTES; HENNING; RIBEIRO, 2015). No entanto, salientamos que a emergência da ciência na modernidade e sua potencialidade presente até hoje se deve a este entendimento de que este método desvelaria as verdades do mundo e colocaria uma ordem no mesmo.

\footnotetext{
${ }^{2}$ Foucault (2009c), ao discutir a função do autor das obras e livros-textos aponta que a originalidade total de um autor é muito difícil de ser determinada, pois ele nasce dentro de um contexto discursivo que lhe permite pensar determinadas coisas e não outras. Por isso, ele prefere o termo instauradores de discurso, visto que estes iniciam uma temática com seus textos que depois se abrem para muitos outros trabalhos de tantos outros autores. Eles "abriram o espaço para outra coisa diferente deles e que, no entanto, pertence ao que eles fundaram" (FOUCAULT, 2009c, p. 22).
} 
Essa ordenação do saber é também característica da organização do discurso pedagógico, emergente junto à massificação do ensino, presente na emergência e constituição da sociedade moderna. Assim, como a ciência promoveu uma forma organizada de conhecer a natureza e a sociedade em comparação ao modo medievo, a pedagogia também emergiu com a organização de um campo que determinava como os sujeitos deveriam ser formados. Essa institucionalização do campo pedagógico propiciou que se estabelecesse um discurso centrado no modo de ensinar e transmitir os conteúdos, o qual Corazza (2008, p. 3) caracterizou como "[...] uma tradição de educar as novas gerações, ensinar-lhes conhecimentos, governar suas atitudes, hábitos, sentimentos, discipliná-las, para que vivam e sobrevivam”. Ao longo do desenvolvimento das pesquisas do campo da pedagogia, o discurso pedagógico sofrera modificações relacionadas às transformações que ocorriam no desenvolvimento da sociedade, passando a determinar as diretrizes mais amplas do que era necessário para se formar os sujeitos. Não apenas preocupando-se com o ensinar e aprender certas coisas e, sim, procurando bases para a formação de sujeitos, ora críticos da sociedade, ora adequados às culturas emergentes da contemporaneidade - teorias críticas e pós-críticas, respectivamente.

Entendemos que ambos os discursos - científico e pedagógico -, ao organizarem-se em torno de objetivos particulares, focos de análise específicos e metodologias próprias para produção de saber foram, e ainda o são, fundamentais na manutenção dos princípios da Modernidade.

Em relação à atualização desses discursos na contemporaneidade, podemos problematizar o quanto o discurso científico, ao aderir às conquistas tecnológicas dos últimos anos, desenvolveu, cada vez mais detalhadamente, suas metodologias e técnicas de produção do saber, o que tem permitido ainda maior efeito de verdade de suas produções, ao passo que o discurso pedagógico, desde sua emergência, no século XVII, com a intensificação da educação das massas, tem modificado as regras de formação de seus discursos, problematizando o currículo e trazendo novas nuances para o campo pedagógico. Hoje, não bastaria mais somente os professores passarem conhecimento para seus estudantes e, sim, seria imperativo que os estudantes pudessem buscá-lo por si mesmos, constituindo-se como agentes de seu processo educativo; e, ainda, que os currículos incorporassem discussões acerca das subjetividades culturais que circulam em nossa atualidade. Ao modificar as regras de formação para a determinação do que seja o processo pedagógico, possibilita-se a emergência de outras formas de produção de conhecimento no campo, outras formas de pesquisa e outras formas de constituir o ensino e a formação de professores dentro das instituições pedagógicas.

Por isto, devido à sua importância na contemporaneidade, pretendemos entender como esses dois discursos anunciam-se na Rede Nacional de Educação e Ciência: Novos Talentos da Rede Pública (RNEC/NT ou, apenas, Rede). A RNEC/NT existe desde a década de 90 do século XX e é composta por mais de 45 grupos de universidades e institutos de pesquisa públicos em todas as regiões do território nacional.

Uma das principais características que confere destaque à RNEC/NT no cenário nacional é que ela é composta por grupos coordenados por professores doutores reconhecidos, nacional e internacionalmente, por suas pesquisas em áreas específicas das ciências naturais, exatas e humanas. Esses pesquisadores, expertos em suas áreas de conhecimento, coordenam seus grupos com auxílio de monitores, geralmente estudantes de pós-graduação das mesmas áreas de atuação dos professores nas universidades que compõem a Rede. 
A principal meta da RNEC/NT é a melhoria das condições de ensino de ciências a jovens carentes de todo o país, buscando novos caminhos para um ensino de ciências eficiente (REDE..., 2013). Para atingir esta meta, os grupos desenvolvem, anualmente, cursos de ciências para professores e estudantes da Educação Básica e promovem estágios em laboratórios de pesquisa dessas instituições direcionadas também a professores e, especialmente, estudantes carentes de Ensino Médio.

Neste trabalho, temos como objetivo analisar como alguns grupos da RNEC/NT da região sul do país operam aquilo que temos chamado discurso pedagógico da ciência em cursos para professores e estudantes da Educação Básica ${ }^{3}$. Brevemente, esclarecemos que entendemos o discurso pedagógico da ciência como aquele que procura aliar as características de um discurso pedagógico pragmático como o referido por Larrosa (1990) - um discurso em que se diz algo a alguém e no qual se quer fazer coisas com o que se disse - às características do discurso da ciência moderna que tem determinado o que pode ou não ser considerado cientificamente válido.

Larrosa (1990, p. 25) aponta que o processo de cientificização da pedagogia, vem sendo "[...] acompanhada de certas operações encarregadas de estabelecer uma certa homogeneidade na produção e na transmissão do saber", tal como apontamos ter ocorrido na constituição do discurso da ciência moderna. Nossa tese é a de que, também para o ensino e propagação do entendimento de ciência nos cursos da RNEC/NT, foi necessário um processo semelhante, uma "pedagogização" da ciência, compondo um discurso pedagógico da ciência.

Em relação à RNEC/NT, em outro texto (SCHWANTES; HENNING; RIBEIRO, 2015), discutimos a atualização do discurso de ciência existente em grupos da região sul da RNEC. Muitos dos grupos analisados se vinculam ao discurso moderno da ciência, proveniente dos entendimentos dos primeiros grupos da RNEC/NT na década de 1980 e da emergência da ciência moderna no século XVII. Muitos grupos entrevistados neste trabalho apontam para uma ciência ainda proveniente dos discursos empiristas e racionalistas de Bacon e Descartes, de uma ciência pautada em um método e na validação e legitimação do que produz. No entanto, nesta mesma análise, percebemos que aparecem nas entrevistas de outros grupos um afrouxamento do discurso de ciência, possibilitado pelas discussões com áreas da ciência menos atreladas a este viés moderno, bem como a vinculação a programas de pós-graduação em Educação em Ciências (SCHWANTES; HENNING; RIBEIRO, 2015).

Neste sentido, esclarecemos que, após a análise do presente artigo, a formulação de um discurso pedagógico da ciência dá-se na operacionalização destes entendimentos do discurso científico dos grupos executores nos cursos para professores e estudantes. Ou seja, há uma aderência de um discurso de ensino ao discurso de ciência para torná-lo compreensível pelo grupo. Entendemos que essa aderência não é superficial, decorrente da junção de dois discursos; ela permite a criação de uma outra maneira de enunciar e descrever a ciência, tornando-a "pedagógica" e constituindo o discurso pedagógico da ciência que será discutido nas análises empreendidas neste texto.

\footnotetext{
${ }^{3}$ Salientamos que este trabalho faz parte de um projeto de Doutoramento cujo problema de pesquisa procura investigar e problematizar o discurso de ciência produzido por seis grupos da RNEC/NT promovido para formação de professores e de novos cientistas.
} 
Assim, apresentaremos nas sessões seguintes: o caminho metodológico, no qual apontamos a produção dos dados por meio de entrevistas com coordenadores e monitores de grupos da região sul da RNEC/NT, bem como descrições dos cursos desenvolvidos por estes grupos. Em seguida, apontamos a análise destes dados, na qual nos pautamos, especialmente, nos estudos arqueológicos foucaultianos, operando com conceitos como discurso, enunciação e cenas enunciativas. E, por fim, apontamos a análise dos cursos no intuito de mostrar o discurso pedagógico da ciência em operação nos cursos da RNEC/NT.

\section{Produção dos dados e metodologia de análise}

Com o desejo de investigar como se constitui o discurso da ciência e o discurso pedagógico da ciência, na RNEC/NT, promovido para formação de professores e de novos cientistas, tomamos como campo empírico quatro grupos de universidades da região sul da RNEC/NT. Esses grupos desenvolvem atividades de pesquisa e extensão nas seguintes áreas de conhecimento: Fisiologia e Bioquímica, ambas áreas do campo das Ciências Biológicas; e duas áreas do campo da Educação, Educação em Ciências e Educação Matemática. Cada um destes grupos é composto por monitores - mestrandos ou doutorandos de Programas de Pós-graduação dessas áreas - e por um coordenador de grupo - professor doutor, reconhecido como pesquisador nas áreas citadas. É interessante salientar que, para pertencer à Rede, o professor coordenador de grupo tem que ser reconhecido por suas publicações em revistas especializadas vinculadas aos seus respectivos campos de pesquisa.

Visitamos estes grupos em suas universidades e produzimos os dados da pesquisa de duas formas: a partir do acompanhamento e da gravação de um curso oferecido a professores e/ou a estudantes em cada universidade investigada e, a partir de entrevistas semiestruturadas com os coordenadores e com alguns dos monitores, também gravadas em vídeo. Destas entrevistas, especificamente para entendermos como o discurso pedagógico da ciência opera nestes cursos, utilizamos como material empírico algumas respostas concedidas pelos coordenadores em relação a duas perguntas específicas ${ }^{4}$ : como ocorre a articulação do entendimento de ciência do grupo no desenvolvimento dos cursos e como se dá a avaliação dos cursos pelo grupo?

Neste trabalho, empregamos algumas ferramentas metodológicas da análise de discurso foucaultiana. Para Foucault (2009a), esta metodologia de análise não procura buscar o que há por trás dos discursos ou o que se pretendia dizer com aquele discurso, e sim, centra seu olhar naquilo que é dito, naquilo que é afirmado no discurso. É uma análise da exterioridade do discurso e não o exame de sua lógica ou de suas intenções internas. Ao pretender acolher cada momento do discurso em uma irrupção de acontecimento, Foucault constitui essa metodologia em um projeto de descrição de acontecimentos. Nas palavras do autor, essas análises são “[...] as do acontecimento e da série, com o jogo de noções que lhes são ligadas; regularidade, casua-

\footnotetext{
${ }^{4}$ Por questões de ordem ética, todos os envolvidos nessa produção de dados - entrevistas e cursos - permitiram o uso de seus depoimentos de forma anônima em um Termo de Consentimento Livre Esclarecido.
} 
lidade, descontinuidade, dependência, transformação; é por esse conjunto que essa análise dos discursos sobre a qual estou pensando se articula" (FOUCAULT, 2011, p. 57).

Partindo dessa definição, empregamos alguns conceitos de análise como discurso, enunciação e cena enunciativa. Trouxemos o entendimento de discurso pedagógico da ciência e retomamos essa discussão no sentido de explicar que os discursos - por exemplo, o científico ou o pedagógico - obedecem a determinadas regras de formação que dão coerência e legitimidade ao que pronunciam. O discurso é o conjunto sempre finito e efetivamente limitado das sequências linguísticas que tenham sido formuladas em um determinado contexto e período de tempo (FOUCAULT, 2009a), ou seja, os discursos são práticas que produzem os objetos dos quais falam.

Outro elemento importante, nessa metodologia de análise foucaultiana, é a enunciação que pode ser definida como a palavra escrita ou falada de um texto oral ou escrito; é um acontecimento que não se repete e tem uma singularidade situada e datada (FOUCAULT, 2009a). Em nosso trabalho, as enunciações são as falas dos componentes dos grupos da RNEC/NT, quando proferidas nas entrevistas ou no desenvolvimento dos cursos. Podemos afirmar que a enunciação analisada isoladamente é apenas enunciação, mas quando inserida em um contexto específico (de sujeito que fala, de local institucional de fala e de posição do sujeito que fala) desenvolve uma relação de sentido e, por isso, pode determinar os elementos que compõem um discurso. Assim, neste texto, à semelhança da metodologia empregada por Knijnik e Duarte (2010), utilizamos as enunciações presentes no material empírico que, mesmo expressas de diferentes modos nas entrevistas e/ou nos cursos, nos remetem à definição de um discurso pedagógico da ciência nos grupos do sul da RNEC/NT.

Elencamos, ainda, que foi necessário criar uma forma de descrever as cenas dos cursos - tratavam-se de cursos com muitas horas de gravação, gerando transcrições de mais de 10 páginas - e desenvolvemos o conceito de cena enunciativa baseadas em Fischer (2001). A autora afirma que uma cena enunciativa "[...] põe em jogo um conjunto de elementos, referentes às possibilidades de aparecimento e delimitação daquele discurso" (FISCHER, 2001, p. 204). Assim, criamos cenas enunciativas (relatos) em que o contexto dos cursos é apresentado tanto pelas enunciações dos monitores e dos participantes, quanto pelas imagens e atividades descritas. Nessas cenas enunciativas, são compiladas observações das atividades gravadas nos vídeos dos cursos observados por nós e enunciações dos coordenadores e monitores, tanto nas entrevistas quanto durante o decorrer dos próprios cursos. Algumas falas destes sujeitos são colocadas literalmente nas cenas enunciativas entre aspas.

Num primeiro momento, descrevemos uma caracterização geral dos cursos observados, compilados no Quadro 1.

Após esta caracterização geral dos cursos, produzimos três cenas enunciativas para análise neste artigo. A primeira delas aponta elementos comuns nos quatro cursos analisados, especialmente ligados à organização do curso e do modo como o grupo conduz o curso. Já na primeira cena, pudemos anunciar algumas práticas pedagógicas colocadas em ação. 
Quadro 1. Características gerais dos quatro cursos observados, aqui denominados C1, C2, C3 e C4

\begin{tabular}{|c|c|c|c|c|c|c|}
\hline Curso & Grupo executor & $\begin{array}{l}\text { Temática } \\
\text { do curso }\end{array}$ & $\begin{array}{l}\text { Público } \\
\text { alvo }\end{array}$ & Duração & $\begin{array}{c}\text { Local } \\
\text { sala de aula }\end{array}$ & $\begin{array}{c}\text { Ano de } \\
\text { observação }\end{array}$ \\
\hline C1 & $\begin{array}{l}\text { professor de pós- } \\
\text { graduação, mestrando } \\
\text { e bolsista de iniciação } \\
\text { científica da área da } \\
\text { Matemática }\end{array}$ & $\begin{array}{l}\text { ensino } \\
\text { Matemática } \\
\text { nos anos } \\
\text { iniciais }\end{array}$ & $\begin{array}{l}\text { professores } \\
\text { de Anos } \\
\text { Iniciais }\end{array}$ & $\begin{array}{l}20 \mathrm{~h} \\
\text { presenciais, } \\
20 \mathrm{~h} \\
\text { distância }\end{array}$ & $\begin{array}{l}\text { da sede da } \\
\text { universidade } \\
\text { na cidade } \\
\text { polo }\end{array}$ & $\begin{array}{l}\text { agosto de } \\
2012\end{array}$ \\
\hline $\mathrm{C} 2$ & $\begin{array}{l}\text { professores de } \\
\text { pós-graduação, } \\
\text { mestrandos, } \\
\text { doutorandos e } \\
\text { bolsistas de iniciação } \\
\text { científica da área das } \\
\text { Ciências Biológicas }\end{array}$ & $\begin{array}{l}\text { método } \\
\text { científico e } \\
\text { radiações } \\
\text { solares }\end{array}$ & $\begin{array}{l}\text { professores } \\
\text { de } \\
\text { Educação } \\
\text { Básica }\end{array}$ & $\begin{array}{l}30 \mathrm{~h} \\
\text { presenciais, } \\
10 \mathrm{~h} \\
\text { distância }\end{array}$ & $\begin{array}{l}\text { sala de aula e } \\
\text { laboratório da } \\
\text { universidade }\end{array}$ & $\begin{array}{l}\text { julho de } \\
2013\end{array}$ \\
\hline C3 & $\begin{array}{l}\text { professor de } \\
\text { pós-graduação, } \\
\text { doutorandos e } \\
\text { mestrandos da área } \\
\text { de Educação em } \\
\text { Ciências }\end{array}$ & $\begin{array}{l}\text { projetos em } \\
\text { Educação } \\
\text { em Ciências }\end{array}$ & $\begin{array}{l}\text { professores } \\
\text { de } \\
\text { Educação } \\
\text { Básica }\end{array}$ & $\begin{array}{l}20 \mathrm{~h} \\
\text { presenciais, } \\
20 \mathrm{~h} \\
\text { distância }\end{array}$ & $\begin{array}{l}\text { anfiteatro } \\
\text { de uma } \\
\text { escola da } \\
\text { cidade }\end{array}$ & $\begin{array}{l}\text { junho de } \\
2012\end{array}$ \\
\hline C4 & $\begin{array}{l}\text { professor de } \\
\text { pós-graduação, } \\
\text { mestrandos e } \\
\text { doutorandos } \\
\text { de Bioquímica } \\
\text { e Educação em } \\
\text { Ciências }\end{array}$ & $\begin{array}{l}\text { método } \\
\text { científico e } \\
\text { fermentação }\end{array}$ & $\begin{array}{l}\text { alunos e } \\
\text { professores } \\
\text { de Anos } \\
\text { Iniciais }\end{array}$ & $\begin{array}{l}25 \mathrm{~h} \\
\text { presenciais }\end{array}$ & $\begin{array}{l}\text { laboratório } \\
\text { de uma } \\
\text { escola da } \\
\text { cidade } \\
\text { próxima }\end{array}$ & $\begin{array}{l}\text { setembro } \\
\text { de } 2014\end{array}$ \\
\hline
\end{tabular}

Fonte: elaborado pelas autoras

Em uma segunda cena, unimos dois cursos - C2 e C4 - por tratarem de uma temática e de uma metodologia de trabalho semelhantes. Ambos os cursos, mesmo abordando conteúdos biológicos diferentes, envolvem os cursistas na utilização do método científico e na sua execução para o trabalho com determinados conteúdos específicos. Além de citarmos as enunciações proferidas nas gravações dos cursos e descrevermos as situações ocorridas nos mesmos, construímos essa segunda cena enunciativa também com enunciações das entrevistas dos coordenadores e dos monitores de $\mathrm{C} 2$ e de $\mathrm{C} 4$.

Por fim, desta mesma forma - alternando descrições de situações dos cursos e enunciações das entrevistas e dos cursos - construímos a terceira cena que conjuga os cursos C1 e 
C3. Esses dois cursos também são articulados juntos por apresentarem metodologia de trabalho, enfoque e temática análogos: ambos focam nas metodologias de ensino, ora da matemática, ora de ciências. Então, na próxima seção, passamos à análise dessas cenas.

\section{Analisando o discurso pedagógico da ciência em operação}

Demarcamos, inicialmente, neste trabalho, os campos pedagógico e científico enquanto campos de saber produtores de discursos necessários para a manutenção das verdades que orientam o funcionamento de nossa sociedade, tal como a entendemos hoje. Ambos, nas palavras de Foucault (2009a, p. 204), têm “[...] esse conjunto de elementos, formados de maneira regular por uma prática discursiva e indispensáveis à constituição de uma ciência, apesar de não se destinarem necessariamente a lhe dar lugar, pode-se chamar saber".

Desta forma, ao pensarmos na RNEC/NT como um todo, definimos que o discurso científico trabalhado nos cursos analisados se refere, na sua grande maioria, ao discurso produzido no espaço do laboratório com suas técnicas, métodos e padrões que são determinantes para a validação de suas pesquisas.

A maioria dos grupos que trabalha nos cursos da Rede está inserida neste modo de pensar a ciência e, assim pode tomar posição no desenvolvimento dos cursos por estar apta a falar do objeto da ciência. Concomitantemente a este entendimento, vimos aparecer, no decorrer dos cursos, um modo de trabalhar, ensinar e apresentar essa ciência para os professores ou estudantes participantes, ou seja, emerge, no desenvolvimento dos cursos, a presença de outros discursos, agora pertencentes a outro campo de saber: a pedagogia.

Tomamos a pedagogia neste texto como um campo de saber determinado historicamente e, portanto, no entendimento de Foucault (2009a), um campo que emergiu de práticas discursivas bem definidas em torno de um determinado número de objetos (por exemplo: ensino, aprendizagem, formação de sujeitos, currículo, etc.), dos conceitos que utiliza para entendê-los (teorias tradicional, crítica, pós-crítica, construtivismo, etc.) e das estratégias que manipula para colocá-los em operação.

Inicialmente, os estudos pedagógicos tiveram, na instituição de ensino escolar, seu principal objeto de estudo (DUSSEL; CARUSO, 2003), com foco nos processos de como ensinar e de como aprender. No entanto, com as modificações sociais e com a ampliação dos discursos em torno da formação dos sujeitos, também se tornou objetivo da pedagogia uma formação que pudesse ocorrer em outras instâncias. Verificamos, nos cursos da RNEC/NT, outros espaços e tempos para constituição de sujeitos e modos de fabricar aquilo que convencionamos chamar de ciência.

Assim, dentro da RNEC/NT, podemos falar em um discurso pedagógico da ciência, pois mesmo que haja um objeto específico - a ciência - no discurso dos coordenadores e dos monitores, este precisa de conceitos, metodologias e outras configurações pertencentes ao discurso pedagógico para ser trabalhado - e ensinado - nos cursos da Rede aqui analisados. É por tal aderência do discurso pedagógico ao saber da ciência, no momento em que esta última passa a ser objeto de ensino nos cursos, que acreditamos haver um discurso pedagógico da ciência na Rede. 
É sobre esse discurso que trataremos a seguir. Ele fica evidenciado na discussão e na apresentação da cena enunciativa que apresentamos. Começamos com a cena comum dos quatro cursos.

\section{Cena enunciativa 1: a potência do discurso pedagógico}

Todos os cursos começaram com os participantes sentados em classes individualmente ou em duplas em algum tipo de sala de aula (anfiteatro, laboratório escolar ou universitário, sala de aula regular - todas com um quadro branco ou de giz) e com a fala do coordenador - muitas vezes com auxílio de projetor multimídia - a frente de todo grupo. Inicialmente eram apresentados os cursos, seus objetivos e o projeto da RNEC/ NT, ao qual os cursos eram vinculados. Em seguida, os monitores e todos os demais componentes da equipe eram apresentados e eram designadas as atividades do primeiro dia dos cursos. Nos dias seguintes, a condução das atividades dos cursos seguia da mesma forma. Na maioria das vezes, eram os monitores que davam as orientações das atividades do dia, que eram seguidas da execução das mesmas pelos participantes com auxílio deles (dos mesmos monitores). Em dois cursos, essas atividades subsequentes eram apresentadas com auxílio de multimídia e, em outros dois, eram feitas de forma oral ou com auxílio do quadro branco.

Um dos cursos concentrou todas as orientações em um primeiro encontro, para depois permitir que os participantes fizessem as atividades em grupo; nos outros três cursos, as orientações eram alternadas com as atividades cuja ação era centrada nos participantes.

Analisando essa primeira cena característica de todos os cursos, visualizamos elementos de um discurso pedagógico em ação em relação aos espaços, aos tempos e aos sujeitos envolvidos. Podemos perceber o local específico da ação pedagógica - a sala -, a disposição do grupo na mesma, a demarcação da posição dos sujeitos na cena - professor/monitor ou coordenador e participante/professor ou estudante da Educação Básica -, a orientação de como proceder e qual o objetivo de cada atividade, assim como a feitura de cada atividade pelo grupo.

Esses elementos, que hoje nos parecem óbvios, quando se trata do ato de ensinar, não são imanentes da prática pedagógica e sim foram constituídos historicamente como tal. Veiga-Neto (2004) afirma que a pedagogia, enquanto campo de saberes que conhecemos, estruturou-se a partir do século XVI, com a emergência da Modernidade. Podemos dizer que este campo, por um processo de emergência semelhante ao vivido pela ciência, é proveniente de um conjunto de práticas antes dispersas no período Medieval. Veiga-Neto (2004) discorre sobre a organização e delimitação que essas práticas passaram no advento da Modernidade até a demarcação disciplinar do que é considerado pedagógico. Embora todas as ações enunciadas nessa cena nos pareçam naturais do processo de ensinar, elas não são transcendentes. São, isso sim, contingentes da história, fabricadas e imiscuídas nas tramas sociais modernas ocidentais.

Muitas são as discussões em torno da delimitação da Pedagogia. Dussel e Caruso (2003), em seu estudo genealógico sobre a sala de aula, apontam dois esquemas para esse campo de saber: ora centram-se na sua determinação como ciência, ora na sua ênfase como uma arte, devido, em especial, às dificuldades de generalização dos resultados dos estudos pedagógicos. 
Neste mesmo viés, Larrosa (1990) aponta que a preocupação dos estudos dessa área deveria enfocar uma visão epistemológica da pedagogia e afirma que não são tão relevantes descrições do que é a pedagogia e, sim, "os efeitos de um conjunto de elementos de construção governados por regras convencionais, heterogêneas e cambiantes" que constituem a pedagogia (LARROSA, 1990 , p. 15, grifo do autor, tradução nossa). Assinalamos o vínculo do autor ao entendimento de discurso foucaultiano, ao afirmar que existem certas regras - que propiciam efeitos de verdade - na qual se apoia a formação discursiva da pedagogia.

Em relação à escola enquanto objeto do campo de atuação pedagógico, Foucault (2002), trabalhando com a disciplina como estratégia de governamento, afirma que esta propiciou a emergência da Modernidade ao permitir uma organização tanto do saber quanto do corpo. Essa disciplina possibilitou um controle do tempo e do espaço dentro de instituições, como os colégios e as escolas, fazendo com que todos aprendam a ocupar os espaços que lhe são devidos - dentro de uma sala de um curso da RNEC/NT, por exemplo: professores a frente da classe, participantes do curso sentados em duplas ou em grupos voltados para frente. Além disso, fazendo com que todos produzam no tempo que lhes é definido - momento específico de fala do coordenador ou do monitor e aquele permitido aos participantes dos cursos, horário em que estes devem apenas ouvir ou no qual devem executar as tarefas. Embora nos pareça apenas uma forma de organização do curso nos grupos, salientamos que todas essas atitudes são aprendidas ao longo de nosso processo de escolarização. Podemos dizer que, nesta primeira cena comum, estão presentes estratégias pedagógicas utilizadas nos cursos da Rede, ou, mais precisamente, nas palavras de Foucault (2002), estratégias disciplinares, que foram e ainda são fundamentais para o processo de ensino e de aprendizagem em qualquer instituição de ensino na contemporaneidade.

É pensando nessas constatações que, na análise dos cursos da RNEC/NT, tomamos a definição de pedagogia apontada por Veiga-Neto (2004, p. 65) como o conjunto de saberes “[...] que dizem como se deve ensinar, como as pessoas apreendem [sic], como devem funcionar as escolas para que a aprendizagem seja mais efetiva, quais os conhecimentos são mais relevantes para compor um currículo, como professoras e professores devem exercer seus ofícios, etc".

Portanto, como descrito anteriormente nos elementos comuns a todos os cursos da região sul da RNEC/NT, temos marcadamente a presença de um aporte pedagógico mesmo que muitos coordenadores tragam, em suas enunciações, que somente fazem nos cursos o que sabem fazer na "bancada" : ciência. Um dos coordenadores, por exemplo, afirmou que nunca teve a preocupação de estudar muito a respeito disso, quer dizer, estudar teorias da educação, e que sempre centrou suas atenções mais na experimentação em laboratório.

As teorias referidas por este coordenador de grupo são aquelas as quais proporcionaram modificações nas regras de formação discursiva dentro da pedagogia e que, para muitos dos coordenadores e monitores da Rede, estiverem presentes somente na sua formação inicial. Segundo Silva (2005), no período de emergência desse campo, a preocupação inicial de uma

\footnotetext{
${ }^{5}$ O termo "bancada" refere-se ao móvel presente na maioria dos laboratórios de pesquisa das ciências naturais e é um modo recorrente dos pesquisadores se intitularem - "pesquisador de bancada" -, referindo-se a sua ação de pesquisar e produzir conhecimento científico dentro dos laboratórios com equipamentos e técnicas específicos.
} 
teoria pedagógica era apenas “saber ensinar”, visto que os conteúdos não eram questionados e a preocupação central era com o procedimento de melhor ensinar aquilo que estava posto. Em seguida, com a teorização crítica, esses conhecimentos passaram a ser questionados no sentido de que ajudavam a reproduzir problemas sociais e econômicos que começavam a emergir na sociedade industrializada. E, por fim, Silva (2005) aponta que no fim do século XX, passaram a fazer parte dessa discussão outros questionamentos que ultrapassavam o problema da manutenção de classes sociais e que compuseram as teorias pós-críticas. Há nessa discussão, questões culturais, identitárias, de gênero, saberes populares e outros. Essa discussão sobre as teorias pedagógicas aparecerá novamente de forma mais profunda em uma outra cena enunciativa.

\section{Cena enunciativa 2: o método científico em foco}

Nestes cursos, a intenção dos monitores e coordenadores foi direcionar os participantes para a vivência do trabalho do cientista apenas através da utilização do método científico, sem enfocar a produção coletiva ou a publicação dos resultados deste método. Em um primeiro momento, os participantes eram questionados sobre o que sabiam sobre a temática ou sobre como fariam para desenvolver a temática de forma prática. Os cursos eram voltados para as etapas do método científico: formulação de perguntas, elaboração de hipóteses, execução de experimentos e término com conclusões. $\mathrm{O}$ coordenador de C4 afirmou: "Se faz ciências [no laboratório], mas o que éciência? [...] Quem trabalha em laboratório é o quê? Cientista. Então, se vocês estão no laboratório, vocês vão bancar os cientistas. E o que o cientista faz? Pesquisa. Então é isso que vocês vão fazer essa semana, vocês vão ser cientistas, ou seja, vocês vão fazer algum tipo de pesquisa".

Em outra enunciação, o coordenador de C4 disse: "Um cientista trabalha com o método cientifico. Primeiro, ele vai ter um problema para resolver, alguma coisa que ele quer saber. [...] Então, depois que se faz várias experiências, a gente tem que observar os resultados. Vocês observaram todo conjunto de resultados. Vocês fizeram experimento segunda, terça, experimentos diferentes, mas observaram tudo que aconteceu. A partir da observação, o cientista cria hipóteses. Sabem o que são hipóteses? O que vocês imaginam que seja. Vocês criaram hipóteses? É uma explicação para aquele fenômeno que vocês observaram".

O coordenador de C2 afirmou que o curso não teria palestras, nem informações, só aquelas provenientes dos experimentos e a partir do que se tinha vontade de aprender: "essasperguntas vocês vão tirar dessas anotações [feitas previamente] e responder com experimentos". No curso C2, os monitores questionavam aos participantes e procuravam não lhes dar respostas, respondendo com outras perguntas e avisando que essas respostas seriam obtidas de modo experimental. Ao passo que, em C4, havia uma maior condução dos monitores devido às características específicas do grupo de professores e estudantes que eram dos anos iniciais. Os monitores de $\mathrm{C} 4$ assumiam as atividades, sempre orientando os participantes globalmente ou pessoalmente em cada grupo.

Em C2, uma participante, em muitos momentos, mostrava que entendia a proposta do curso como, por exemplo, ao dizer "a hipótese só será aceita após um teste experimental" ou "eu entendi o que vocês querem fazer, tem que sair das minhas deducões, é um desmanche do padrão educacional que o aluno não tenha só o conhecimento do professor". Em resposta, uma monitora de C2 enunciou: "mas o que é legal dessa metodologia é que tu não precisas ter aporte teórico para 
chegar às tuas conclusões", sendo complementada pelo coordenador de C2: "isso que é o método cientifico".

Em uma enunciação de entrevista, o coordenador de C2 afirmou: "Sem ter o modelo que eu tenho que seguir à risca, a ideia da descoberta de fazer o aluno descobrir. Mesmo o professor, enquanto aluno naquele momento, é fundamental".

As atividades de C4 eram também sempre práticas e, logo após sua execução, havia uma discussão sobre o que foi feito e os princípios da ciência e do método ligados àquela atividade. Igualmente na $\mathrm{C} 2$, no início de cada dia, era retomado o que foi feito no dia anterior. Nessas discussões eram feitas perguntas relacionadas ao tradicional método científico como "o que você usou no teu experimento? Você observou o quê?? Fala pra gente o que você observou quando uson o azeite. E o que aconteceu? Olha a observação dela, ela viu, ela fez. e viu acontecer, no experimento dela."

Em outra enunciação de entrevista, também o coordenador de C4 se referiu ao método da ciência para o ensino: "Dentro do método científico. Usar isso [o método científico] como uma ferramenta. Você vai fazendo, dependendo do local onde você está, vai se adaptando, não existe tema, não existe assunto especifico".

A aderência do discurso pedagógico aos cursos, para promover o entendimento do método científico da ciência, aparece muito marcadamente na cena enunciativa que aponta as peculiaridades de dois cursos: C2 e C4. Na descrição dessa cena, podemos identificar que a temática central dos cursos é o método científico enquanto atividade própria dos cientistas no laboratório. O que vemos são professores e estudantes trabalhando apenas com o método científico individual e isoladamente. Provocamo-nos a pensar o quanto esses cursos podem ser potencializadores de modos de fazer ciência, convidando os cursistas a pensar a ciência de modo coletivo. No entanto, a cena não registra isso. Mas também há presença do discurso pedagógico que ensina, através do direcionamento e da orientação dos monitores em como entender e colocar em ação esse método. Há uma pedagogização para que os alunos aprendam ciência e isso continua a nos evidenciar os dois campos de saberes colocados em ação: a pedagogia e a ciência. Sendo assim, a organização do curso depende de ações pedagógicas que facilitem o entendimento da produção da ciência. Mesmo que se trate de campos de saberes separados, com suas regras específicas de formação discursiva, há um atravessamento pedagógico no ensino da ciência.

Apesar dessas enunciações na cena vincularem-se à prática de experimentação presente na pesquisa em laboratório feita pelos entrevistados, avaliamos que o discurso pedagógico entra como ferramenta para tornar o discurso científico do método acessível. Podemos afirmar que há uma tentativa de pedagogizar o método usado e vivido na pesquisa científica para o momento e o público do curso. Dussel e Caruso (2003) apontam essa preocupação com o ensino desde a história medieval, tanto com o ensino do catolicismo, quanto com o ensino dos modos de se portar direcionado aos príncipes da nobreza. Com os movimentos de produção de uma nova era social não feudal, no século XVI, a ampliação do ensino para o governo e condução de todos os indivíduos alicerçou a emergência da ação pedagógica, pautando-se, em parte, na técnica disciplinar discutida por Foucault (2002). Com isso, alguns saberes específicos, posturas e modos de agir - segundo Foucault, todos disciplinares - foram considerados importantes e necessários para a condução de todos, constituindo-se em condições de possibilidade para 
o surgimento de diferentes metodologias de ensino que possibilitariam a transmissão desses saberes de uma forma que todos pudessem aprender.

Além das orientações enunciadas nos cursos citados para o ensino e aprendizado do método da ciência, problematizamos a própria pedagogização do método científico, definido pelas cinco etapas citadas na cena enunciativa 2. Essa pedagogização resulta tanto nas devidas explicações de como proceder com o método, no momento de efetivação do curso como visualizado na referida cena, quanto uma didatização histórica dos métodos do experimentalismo de Bacon e do racionalismo de Descartes. Isto é, além destes esclarecimentos de como agir com o método científico para facilitar seu entendimento pelo público dos cursos, marcamos outro movimento de "pedagogização" do método científico ao longo da história da ciência. A proveniência do método, hoje legitimado como próprio e exclusivo da ciência, deu-se, principalmente, com as publicações de Bacon e Descartes no século XVII.

Descartes (2008), no período histórico em que foi dada maior importância à razão humana como forma de determinação das verdades do mundo, pós Idade Média, apontou alguns preceitos lógicos necessários para uma boa condução da razão. Eram eles: aceitar como verdadeiras somente ideias claras e distintas, e perguntar-se sobre aquelas que têm dúvida; dividir cada objeto em quantas partes forem necessárias para melhor entendê-lo; ordenar as ideias das mais simples às mais complexas; e fazer revisões completas e generalizações. Desta forma, Descartes destaca que as verdades são alcançadas pelo uso da razão e podemos perceber, nesses preceitos, algumas ações descritas como próprias do método científico atual: perguntar (primeiro preceito), analisar (segundo e terceiro preceitos) e generalizar (quarto preceito).

No entanto, não foi somente Descartes que contribuiu para a emergência desse método, pois uma etapa relevante do mesmo e que mais efetivamente isola o método científico de outras metodologias de pesquisa é proveniente da obra de Bacon (1984): a experimentação.

Bacon (1984), ao procurar determinar as "verdadeiras indicações acerca da interpretação da natureza" - subtítulo de um de seus livros - aponta a importância da metodologia da experimentação nessas descobertas sobre a natureza. Sua maior preocupação era com a prática, que os conhecimentos não fossem apenas teorias e, sim, que tivessem uma aplicação. Por isso, afirmou que seu objetivo era "deduzir das obras e experimentos as causas e axiomas e, depois, das causas e princípios, novas obras e experimentos, como cumpre aos legítimos intérpretes da natureza" (BACON, 1984, p. 76). Ou seja, a maior contribuição dos escritos de Bacon vem a compor a quarta etapa do método científico pedagogizado - a experimentação.

A partir dos entendimentos desses dois pesquisadores é que o método científico foi compilado. Podemos afirmar que houve aqui também um processo de pedagogização da metodologia baconiana e cartesiana, já que o conhecido método científico das cinco etapas observação, formulação de perguntas, desenvolvimento de hipóteses, experimentação e conclusão - não está evidentemente presente na emergência da ciência moderna no século XVII. Esse método, que hoje conhecemos, é um método didatizado com suas origens marcadas no empirismo e no racionalismo.

Observamos durante muitas enunciações dos monitores e dos coordenadores, já citadas na cena 2, que eles demonstram a necessidade de uma explicação oral, etapa a etapa, de como colocar o método científico em prática no curso. Além disto, o movimento de pedagogizar o método para seu ensino aparece na própria estruturação dos cursos ao longo dos dias. Em um deles, cada etapa do método correspondia a um dia de trabalho para que fosse apropriado 
pelos participantes aos poucos. Assim, o primeiro dia era destinado aos conhecimentos prévios dos participantes e à preparação de perguntas; o segundo dia era a elaboração de hipóteses; o terceiro e quarto, dedicado aos experimentos, e no quinto dia a discussão da comprovação ou não das hipóteses iniciais. Já a estrutura do outro curso possibilitava que em cada dia fosse feito um experimento, trabalhando desde a elaboração da pergunta até a execução do experimento todos os dias do curso. Deste modo, ambos os cursos demarcam a importância de conhecer e saber executar o método científico propagado pela modernidade.

Por isso, com essas discussões, acreditamos que há dois movimentos nos quais o discurso pedagógico pode ser aliado ao científico nos cursos analisados até aqui: um movimento histórico na compilação do método científico das cinco etapas a partir dos compilados de Bacon e Descartes; e outro movimento pedagógico presente no "como" ensinar o método científico nos cursos.

\section{Cena enunciativa 3: metodologias para um "melhor" ensino}

Os cursos C1 e C3 foram organizados para desenvolver o trabalho com materiais e metodologias de ensino para grupos de professores. Para tanto, ora discutiram metodologias teoricamente com todo o grupo para, em seguida, grupos menores de professores pudessem colocá-las em ação; ora já trabalhavam em pequenos grupos de professores com as metodologias e seus materiais associados, como no caso do material concreto de matemática. Algumas vezes, as discussões em torno da metodologia envolveram também um repensar sobre os conteúdos e a prática pedagógica dos docentes. Esse interesse é exemplificado pela enunciação da coordenadora de C1, que afirmou: "[o professor] repetia aquilo que estava no livro, porque aquilo é verdadeiro, está legitimado por alguém. [...] Mas a gente começa a questionar no curso. Uma das atividades que a gente propõe no curso é que eles vão planejar uma atividade com os alunos deles e vão fazer essa reflexão do que aconteceu na sala de aula conosco".

Já em uma enunciação do coordenador de C3, percebe-se a preocupação com a variação de métodos em sala: "Se eu não tentar buscar o diferente [em uma metodologia], vai ficar muito cômodo pra mim e eu vou acabar replicando aquilo que às vezes a gente critica que os professores da escola fazem que é a acomodação. Então, eu tenho que ir em busca de uma coisa diferente, pra não cair naquela rotina de já saber o que vai acontecer [na sala de aula]".

Neste sentido, em C1, um dos monitores comentou sobre o mito de que "matemática é difícil, que é muito abstrata", dizendo ser necessário entender os porquês de determinadas regras e algoritmos a fim de modificar as metodologias de ensino. Ele pediu aos professores que participassem do curso, contando experiências, perguntando e participando. Também comentou a importância da participação no curso "para aprender matemática, a gente tem que ousar, tem que manipular, tem que querer fazer, então é isso que a gente vai trabalhar com vocês, que vocês participem, que vocês comentem, que vocês perguntem, tragam contribuições pois, de repente, as atividades que nós vamos hoje trabalhar com vocês, vocês já fizeram, mas de uma outra maneira, com outro foco".

Durante todas as atividades do curso C1, esse grupo preocupou-se muito com a mudança do entendimento da matemática como cálculo e com a compreensão da sua proposta para o ensino pelos professores, bem como preocupou-se com a aplicação 
das metodologias na escola, fazendo muitas relações diretas com o ensino em sala de aula. Um monitor comentou: "Não basta levar o material para sala de aula e não formalizar depois os conceitos. [...] É importante, depois das atividades, a gente falar dos conceitos que foram trabalhados, que foram explorados. A gente faz uma reflexão dos conceitos". Todas as atividades eram voltadas para metodologias de ensino escolares e reflexão docente sobre as mesmas. Já no curso C3, um dos monitores assumiu a fala explicitando o amparo teórico no qual a metodologia seria trabalhada: a interdisciplinaridade e os temas transversais. Em seguida, outro monitor centrou-se na questão do tema gerador ciência e dos métodos de ensino alternativos como a metodologia de problematização e o uso do arco de Marguerez, que é a metodologia empregada e estimulada no curso. Exemplificou a necessidade de mudança de metodologia devido ao fato de os alunos estarem conectados com a internet e poderem ter as respostas que quisessem a todo o momento muito rapidamente. Também sobre a variação de metodologia, o coordenador de C3 destacou no curso: "eu posso dizer pra vocês que eu ainda não consegui repetir uma mesma maneira de tentar ensinar [...] nossa intenção aqui não é dar uma fórmula pronta".

$\mathrm{Na}$ entrevista, o coordenador de C3 enunciou: "[os monitores] vão lá e teorizam, quer dizer, a parte experimental do curso é os professores irem para a escola e desenvolverem um projeto teórico. O professor vai propor um projeto com os alunos".

E foi assim o desenvolvimento do curso C3: os participantes foram reunidos em grupos por escola e seguiram desenvolvendo as etapas da metodologia de ensino exemplificadas pelos monitores e construindo uma proposta a ser feita na escola. Os monitores circulavam entre os grupos para tirar possíveis dúvidas bem como auxiliar com ideias.

Nessa cena, a ênfase passa a ser nas metodologias de ensino no intuito de possibilitar a compreensão das temáticas, sejam estas a ciência ou a matemática. Desde o início dos mesmos, é demonstrada, pelas enunciações dos monitores e dos coordenadores, a preocupação em variar as metodologias de ensino e entender como estas podem auxiliar o entendimento de conteúdos específicos.

Os elementos pedagógicos, inicialmente discutidos na cena geral dos cursos, aparecem novamente nessa aqui, pois há uma orientação explícita no que os professores devem fazer no decorrer do curso, tanto teórica quanto praticamente: inicialmente ouvem os monitores e coordenadores sobre materiais e metodologias e depois realizam as partes ditas práticas dos cursos com a elaboração de atividades para desenvolver em suas escolas. Aqui, podemos avançar na discussão sobre o discurso pedagógico da ciência, vinculando-o ao desenvolvimento histórico das teorias pertencentes ao campo pedagógico. O objetivo dos cursos é que, ao utilizar esses elementos do campo pedagógico, os professores cursistas possam melhorar suas práticas docentes.

Silva (2005) e Veiga-Neto (2004) afirmam que as teorias do campo pedagógico foram desenvolvidas, historicamente, atreladas aos acontecimentos sociais, econômicos, políticos e culturais de cada período. Por exemplo, quando o ensino obrigatório foi instituído, havia necessidade de estabelecer melhores tecnologias de ensino, ou quando a industrialização permitiu o desenvolvimento de uma classe trabalhadora e uma classe dominante na sociedade, as discussões para um currículo crítico foram empregadas. Por isso, na contemporaneidade discute-se que muitas estratégias pedagógicas devem ser revistas para que abranjam a diversidade presente em nossa sociedade atual, pensando em outros modos de ensinar. 
Ramos do Ó e Costa (2007) já apontavam esse descompasso, ao afirmar que o ensino e as instituições escolares ainda se pautam na homogeneidade para a formação dos sujeitos característica do modelo racionalista da educação do século XIX - e afirma que os sujeitos que frequentam as escolas são compatíveis com as mudanças do século XXI, que aprendem desde cedo a lidar com as contradições no domínio da vida social. Para os autores, seria possível diminuir esse distanciamento no momento em que o professor mudasse sua postura ao imaginar "alguém que pudesse, digamos assim, mais do que ser o porta-voz das verdades, ser alguém cujo trabalho se concretizasse no exercício criativo de seus alunos" (RAMOS DO Ó; COSTA, 2007, p. 111).

Já o estudo de Sommer (2007) demonstrou que, entre os discursos produzidos no campo pedagógico que chegam até a escola, há a constituição de um discurso vigente, considerado válido e produzido de acordo com o que é determinado nas pesquisas do campo. Assim, o autor realizou entrevistas com professoras de anos iniciais, perguntando sobre sua prática docente, e percebeu que há discursos que parecem ser evitados por elas por não fazerem mais parte da produção discursiva pedagógica aceita atualmente. Ou seja, nas palavras de Foucault (2011), são as chamadas interdições que sofrem o discurso. Há termos ausentes no discurso das professoras por aderirem a um discurso pedagógico tido como "ultrapassado", como, por exemplo: ensino, metodologia e planejamento (SOMMER, 2007). E, no entanto, são estas expressões que aparecem na cena 3 dos cursos da RNEC/NT.

Mesmo interditados no discurso das professoras do trabalho de Sommer (2007), percebemos que, na cena 3, a tentativa dos grupos de uma atualização do discurso pedagógico da ciência para melhoria do trabalho docente nas escolas é justamente nas metodologias de ensino - os materiais concretos em C1 ou a problematização e o arco de Marguerez em C3. E, além dessa aposta nas metodologias, os grupos procuram enfocar também a discussão em torno de uma mudança de postura e planejamento docente.

Silva (2005), em seu livro sobre as diferentes teorias que dão suporte ao currículo ao longo dos anos, aponta, assim como Corazza (2005) e Veiga-Neto (2004), três discursos pedagógicos: teoria tradicional, teoria crítica e pós-crítica. A teoria tradicional, ou nas palavras de Corazza (2005), reprodutivista, emerge no contexto da industrialização e de quando se iniciou o processo de escolarização em massa. Tendo sido instituído que todos os indivíduos da sociedade deveriam ser "educados" e, para tal, deveriam aprender determinados conteúdos, restava a esses discursos reprodutivistas o estabelecimento de como este processo se daria, limitando suas inquietações às técnicas e às metodologias de ensino, aos seus resultados e às suas avaliações (SILVA, 2005). Esse processo de escolarização, segundo Dussel e Caruso (2003), ou até mesmo antes da instituição "escola" existir concretamente - por exemplo, nos períodos de ensino direto na monarquia, nas instituições catequistas ou nos campos de jesuítas - foi, e ainda é, a forma inicial encontrada para a condução dos sujeitos na sociedade desde a mais tenra idade.

Silva (2005) comenta que essa preocupação se modificou a partir da década de 1960 do século 20, quando movimentos estudantis e de independência de colônias, por exemplo, propiciaram o questionamento sobre os objetivos das instituições de ensino como, por exemplo: a que tipo de sujeito esse ensino se destinava? Por que deveriam ser ensinados tais conteúdos e não outros? A quem estas formas de conhecimento dominantes serviam?

Esses questionamentos propiciaram a proveniência das teorias críticas que passaram a se preocupar com o tipo de conhecimento que estava sendo ensinado, procurando respostas para as razões de ele estar presente nos currículos de instituições pedagógicas, localizando-o 
no lado da sociedade que continha "o" poder. A teoria crítica não se preocupava somente com uma forma metodológica neutra de como melhor ensinar o conhecimento mas, sim, com os motivos que levavam tal conhecimento a ser ensinado. Palavras como emancipação, libertação, ideologia e conscientização entram no discurso pedagógico de forma tão potente que, até em uma pesquisa mais recente como a de Sommer (2007), elas ainda aparecem marcando o discurso pedagógico atual.

Dadas as diretrizes dessas duas teorias educacionais, podemos afirmar que os cursos da RNEC/NT analisados, cuja ênfase se dá nas metodologias de ensino, fazem parte do escopo de preocupação das teorias tradicionais do currículo (SILVA, 2005). Os cursos C1 e C3 centram suas discussões na possibilidade de melhoria do trabalho do professor nas técnicas de ensino, seja o material concreto em matemática ou o tema gerador, seja o arco de Marguerez nas ciências. Ou seja, a princípio, o conteúdo a ser ensinado está estabelecido, no entanto, o caminho que será feito para colocá-lo à baila é a grande questão a ser modificada e melhorada.

Deste modo, assim como discutido na cena enunciativa 1 , as metodologias de ensino também são construções históricas engendradas a partir de diferentes saberes e práticas. Segundo Veiga-Neto (2004, p. 70), “[...] enquanto que a ordem medieval era pensada como aberta e infinita e, portanto, incerta ou aproximada, a ordem moderna passa a ser pensada como fechada e finita e, portanto, certa e exata". Considerando esse entendimento do autor, se temos uma ordem "nova", exata e correta para entender o mundo capitaneada pela ciência que precisa ser entendida por todos, abre-se a possibilidade de que emerjam diferentes metodologias para o ensino para possibilitar a compreensão deste mundo. É por este caminho que os cursos da Rede parecem vir trabalhando na sua formação com professores. E para que uma metodologia de ensino gere resultados positivos - que seriam determinados pela melhor aprendizagem dos estudantes da Educação Básica -, ela deve ser bem planejada. O planejamento aparece também nos cursos como forma de "colocar em prática" o alicerce metodológico previamente discutido, ora em pequenos grupos, no mesmo período do curso como em C3, ora à distância, para uma apresentação posterior como em C1.

Veiga-Neto (2004) e Larrosa (1990), em suas análises sobre a pedagogia, criticam a eterna busca da produção normativa da área e da "melhor" metodologia para a prática do ensino. Afinal, se acreditamos que não temos como dar conta de uma única resposta para o mundo flexível e dinâmico em que nos encontramos, não há como determinarmos a melhor metodologia a trabalhar neste mundo. Mesmo assim, Veiga-Neto (2004) confirma que a pedagogia está "sempre à espera de uma nova e definitiva teoria, de uma nova ou definitiva fórmula, de um novo ou definitivo método que finalmente deem conta dos males deste mundo cavernoso" (VEIGA-NETO, 2004, p. 77). Podemos visualizar essa "crença" nos cursos da Rede apontados anteriormente e nas enunciações dos coordenadores entrevistados que anunciam a ênfase metodológica na formação de professores como sua aposta para melhoria do ensino de ciências.

Além disto, há outra questão interessante a ser apontada nesses cursos. Em especial, durante o curso C1, parece haver uma grande preocupação com o questionamento do professor em relação às metodologias empregadas em sala de aula bem como com o entendimento e a capacidade de reflexão do professor sobre as mesmas. Voltando às teorias trazidas por Silva (2005), parece haver em C1 uma aproximação ao discurso pedagógico crítico cuja preocupação é com a negação das estruturas reprodutivas que mantém o status quo da educação escolarizada. Estimulando que o professor repense sua posição enquanto autor das metodologias e de seus 
planos - questionando sobre o que ensina, que tipo de sujeito está ajudando a formar, por que ensina de tal forma - e estimulando isso em seu curso, os monitores de C1 possibilitaram um repensar da prática docente, como na teoria crítica que reconhecia "a tendência histórica da instituição escolar em produzir a repetição dominante, porém apontava possibilidades e experiências de contestação, de movimentos contra-hegemônicos, de rupturas ideológicas" (CORAZZA, 2005, p. 105). Assim, mesmo com a marcante presença do discurso pedagógico tradicional na cena de C1 e C3, percebemos uma abertura para a problematização desse discurso, promovendo uma aproximação com o viés crítico das teorias educacionais.

Com estas análises dos cursos do sul da RNEC/NT, apontamos a necessidade de aderência a um discurso pedagógico da ciência, ora enfatizando o ensino do método científico, ora a variação de metodologias de ensino da ciência, para a efetivação da formação de jovens cientistas ou de formação continuada de professores da educação básica. Concluímos ainda que, para que a Rede consiga atingir suas metas de melhoria do ensino e do acesso à ciência por jovens carentes, essa articulação entre os discursos dos dois campos de saber é muito produtiva.

Ao pensarmos que os discursos são mutáveis, dadas às condições em que sua formação se dá, e que, segundo um viés foucaultiano, as regras de formação do discurso modificam-se de acordo com os sujeitos, o local e o tempo em que são produzidos, podemos entender que os quatro cursos utilizam, com ênfases diferentes, elementos do discurso pedagógico incorporados ao discurso científico, ou vice-versa, compondo outra formação discursiva que compreende novas regras para a operacionalização deste discurso nos cursos da RNEC/NT analisados. Essa outra formação discursiva é o que chamamos discurso pedagógico da ciência. De um lado, está o discurso pedagógico da ciência nos cursos 2 e 4 da cena enunciativa 2 tratando especialmente do método; de outro, os cursos 1 e 3 da cena enunciativa 3 , enfocando as metodologias de ensino em ciências.

Nos quatro cursos, o discurso pedagógico da ciência constitui-se nas diferentes formas e estratégias com que é colocado em operação o discurso científico. Por isto, podemos dizer que os grupos da região sul, de alguma forma, operam com o discurso pedagógico da ciência em seus cursos, partindo de pressupostos e elementos dos campos da pedagogia e da ciência.

\section{Considerações finais}

A partir deste trabalho, podemos perceber movimentos de pedagogização da ciência nos cursos do sul da RNEC/NT de três formas: na organização pedagógica geral do curso; no ensino ou, como denominamos, na "pedagogização", do método científico; e na variação de metodologias para o ensino de ciências. A pedagogização da ciência nos cursos da Rede atende às especificidades didáticas do campo da pedagogia, pois há preocupação com o entendimento de como se dá a produção da ciência por meio do método e de como se pode favorecer o seu entendimento pelas metodologias variadas de ensino. Esta sutil interação da ciência com a pedagogia nos cursos nos mostra o quanto estes dois discursos são bem determinados e têm especificidades que lhes são próprias, mas também o quanto, ao aparecerem e trabalharem juntos nos cursos, permitem uma produtividade maior do ensino de ciências e maior alcance da ciência e seu ensino à população.

Com esses apontamentos, reafirmamos a presença de um discurso pedagógico da ciência nos cursos, no sentido de que este é produzido no interstício dos dois campos de saber: 
a pedagogia e a ciência. Além disto, a produtividade da união desses dois campos favorece o alcance do objetivo geral da Rede que é "a melhoria das condições de ensino de ciências a jovens carentes de todo o país" (REDE..., 2013).

Neste sentido, é possível dizer que cursos como esses analisados possibilitam ao professorado compreender a importância desses dois campos de saberes para sua prática docente: o discurso pedagógico e o discurso científico. Conhecendo outras possibilidades de ensino científico e, repensando suas práticas pedagógicas, os cursos RNEC/NT se mostram produtivos na formação continuada de professores no ensino de ciências.

A análise aqui apresentada, também nos permite concluir que as raízes modernas da pedagogia e da ciência estão muito presentes nas práticas docentes dos grupos executores dos cursos. Mesmo que o contexto de mundo atual esteja permeado por alterações sociais, políticas e econômicas no projeto moderno de sociedade do século XVII, ainda desenvolvemos o nosso trabalho docente pautado em características daquele projeto. Isto mostra a potência que as concepções modernas de mundo ainda têm na determinação da contemporaneidade - especificamente, aqui, a disciplinarização da pedagogia e o efeito de verdade do método da ciência. Mesmo que alguns dos cursos apontem uma abertura para uma discussão crítica e reflexiva do trabalho docente, ainda é dentro dos princípios modernos que falam, pois há algo fundamental a ser ensinado e há uma metodologia mais adequada para tal.

Por isto, que ainda sejam essas balizas modernas que nos constituem hoje, produzindonos enquanto sujeitos, fabricados nas tramas dessa episteme, e atuantes, no trabalho docente, também ainda dentro dessas referências modernas.

\section{Referências}

BACON, F. Novum Organum: verdadeiras indicações acerca da interpretação da natureza. São Paulo: Abril cultural, 1984.

CORAZZA, S. M. Currículo na contemporaneidade. Brusque: UNIFEBE, 2008.

Disponível em: < https://www.unifebe.edu.br/04_proeng/formacao_continuada/2008_2/ material_palestras/curriculo_na_contemporaneidade.pdf>. Acesso em: 10 jun. 2016.

. Planejamento de ensino como estratégia de política cultural. In: MOREIRA, A. F.

(Org.). Currículo: questões atuais. Campinas: Papirus, 2005. p.103-143.

DESCARTES, R. O discurso do método. Petrópolis: Vozes, 2008.

DUSSEL, I.; CARUSO, M. A invenção da sala de aula: uma genealogia das formas de ensinar. São Paulo: Moderna, 2003.

FISCHER, R. M. B. Foucault e a análise do discurso em educação. Cadernos de Pesquisa, São Paulo, n. 114, p. 197-223, 2001. Disponível em: < http://dx.doi.org/10.1590/S0100$15742001000300009>$. Acesso em: 10 jun. 2016.

FOUCAULT, M. Arqueologia do saber. Rio de Janeiro: Forense Universitária, 2009a. p. $94-99$.

Genealogia e poder. In: . Microfísica do poder. São Paulo: Graal, 2009c. 
FOUCAUlT, M. A ordem do discurso. 21. ed. São Paulo: Loyola, 2011. p. $12-25$.

Verdade e poder. In: . Microfísica do poder. São Paulo: Graal, 2009b.

Vigiar e punir. Petrópolis: Vozes, 2002.

HENNING, P. C. A modernidade líquida e o borramento de fronteiras no campo das ciências. Revista de Estudos Universitários, Sorocaba, v. 36, n. 1, p. 53-65, 2010. Disponível em: <http://repositorio.furg.br/handle/1/1627>. Acesso em: 10 jun. 2016. HENNING, P. C. Profanando a ciência: relativizando seus saberes, questionando suas verdades. Currículo sem Fronteiras, [Lisboa], v. 7, n. 2, p. 158-184, 2007. Disponível em: $<$ http:/ /www.curriculosemfronteiras.org/vol7iss2articles/henning.pdf > . Acesso em: 10 jun. 2016.

KNIJNIK, G.; DUARTE, C. G. Entrelaçamentos e dispersões de enunciados no discurso da educação matemática escolar: um estudo sobre a importância de trazer a "realidade" do aluno para as aulas de matemática. Bolema, Rio Claro, v. 23, n. 37, p. 863-886, 2010. Disponível em: <http://www2.rc.unesp.br/bolema/?q=node/153>. Acesso em: 10 jun. 2016.

LARROSA, J. E1 trabajo epistemológico en pedagogía. Barcelona: PPU, 1990.

RAMOS DO Ó, J.; COSTA, M. V. Desafios à escola contemporânea. Educação \& Realidade, Porto Alegre, v. 32, n. 2, p. 109-116, 2007. Disponível em: <http://seer.ufrgs.br/ educacaoerealidade/article/view/6653>. Acesso em: 10 jun. 2016.

REDE Nacional de Educação e Ciências. Disponível em: <http://www.educacaoeciencia. net.br>. Acesso em: 15 mar. 2013.

SCHWANTES, L.; HENNING, P. C.; RIBEIRO, P. R. C. Fazer o desconhecido ser descoberto: atualização nos modos de enunciar a ciência nos grupos da região sul da Rede Nacional de Educação e Ciência - Novos Talentos da Rede Pública (RNEC/NT). Ensaio: pesquisa em educação em ciências, Belo Horizonte, v. 17, n. 1, p. 173-191, Jan/Abr, 2015.

SILVA, T. T. Documentos de identidade: uma introdução às teorias do currículo. 2. ed. Belo Horizonte: Autêntica, 2005.

SOMMER, L. H. A ordem do discurso escolar. Revista Brasileira de Educação, Rio de Janeiro, v. 12, n. 34, p. 57-67, 2007.

VEIGA-NETO, A. Algumas raízes da pedagogia moderna. In: ZORZO, C.; SILVA, L. D.; POLENZ, T. (Org.). Pedagogia em conexão. Canoas: ULBRA, 2004. p. 65-83.

Artigo recebido em 14/07/2015. Aceito em 25/10/2015.

Endereço para contato: Avenida Itália, km 8, CEP 96201-900, Rio

Grande, RS, Brasil. 